Суворова Е.И.

КОНЦЕПТУАЛЬНЫЕ ПОДХОДЫ

К ИСПОЛЬЗОВАНИЮ РЕЗУЛЬТАТОВ

ГЕНЕТИЧЕСКИХ ИССЛЕЛОВАНИЙ В СФЕРЕ ЛИЧНОГО СТРАХOВАНИА 1

\title{
Suvorova E.I. \\ CONCEPTUAL APPROACHES TO USING THE RESULTS OF GENETIC RESEARCH IN THE FIELD OF PERSONAL INSURANCE2
}

\begin{abstract}
Доступность и высокая информативность результатов генетических исследований требуют от законодателя решения вопросов о пределах их использования в различных сферах общественной жизни, в том числе при заключении договоров страхования. Целям страхования в большей степени отвечает таргетное секвенирование генома, хотя при мутации de novo, выявление заболевания возможно только при проведении экзомного секвенирования.

Проведенное исследование позволило сделать вывод о необходимости нормативного правового регулирования вопросов использования результатов генетических исследований при осуществлении личного страхования. При этом следует исходить из дифференцированного подхода к диагностическим и прогностическим тестам, распространяя ограничения только на последние; возможности регламентации этих отношений на уровне саморегулирования при контроле ключевых позиций со стороны Центрального банка РФ как регулятора рынка страховых услуг; допустимости использования результатов генетического тестирования в сфере добровольного личного страхования в случае: заключения договора на сумму выше установленных пределов; необходимости опровержения семейного анамнеза с целью выработки более благоприятных условий страхования при наличии соответствующего волеизъявления страхователя; целесообразности создания биобанка данных в том числе с целью обеспечения возможности доступа страховщиков к обезличенной статистической информации. В то же время нельзя не признать, что во многих аспектах отсутствие доступа к генетическим данным вполне компенсируется традиционными актуарными методиками.
\end{abstract}

Ключевые слова: прогностические тесты, страхование, биобанк, недискриминация, «право на незнание».

The availability and high information content of the results of genetic research require the legislator to decide on the limits of their use in various spheres of public life, including when concluding insurance contracts. Targeted genome sequencing is more appropriate for insurance purposes, although for de novo mutations, disease detection is only possible when exomic sequencing is performed.

The research made it possible to conclude that there is a need for regulatory regulation of the use of genetic research results in the implementation of personal insurance. At the same time, we should proceed from: a differentiated approach to diagnostic and predictive tests, extending restrictions only to the latter; the possibility of regulating these relations at the level of self-regulation

1 Исследование выполнено при финансовой поддержке Российского фонда фундаментальных исследований (РФФИ) в рамках научного проекта № 18-29-14056

2 The reported study was funded by RFBR according to the research project № 18-29-14056 
while controlling key positions by the Central Bank of the Russian Federation as the regulator of the insurance market; the permissibility of the use of genetic testing results in the sphere of voluntary personal insurance in case of a contract for the amount above the established limits; the necessity of refutation is a family history in order to develop a more favorable terms of insurance with the appropriate will of the insured; the feasibility of establishing a Biobank data including the purpose of ensuring the access of insurers to the impersonal statistical information. At the same time, it is true that in many aspects the lack of access to genetic data is fully compensated for by traditional actuarial methods.

Keywords: predictive tests, insurance, biobank, non-discrimination, "right to ignorance».

При осуществлении личного страхования выявление факторов, влияющих на вероятность наступления страхового случая, является серьезной проблемой, которая российскими страховщиками в настоящее время преимущественно решается на основе статистических показателей и анализа данных, представленных страхователем в заявлении на страхование и/или анкете, иногда затрагивающей семейный анамнез. В зарубежной практике все чаще поднимается вопрос о расширении источников получения необходимой информации, в том числе генетической, чему в значительной мере способствуют темпы развития науки, позволяющей получать ранее недоступную информацию прогностического характера.

Долгое время объективным препятствием для этого была дороговизна подобных исследований. Однако используемые методики постоянно совершенствуются, что способствует существенному снижению их стоимости. Поворотным моментом стала практика использования платформ секвенирования «второго поколения» (NGS), сменившая методику Сенгера, позволявшую одновременно секвенировать только один фрагмент ДHК. NGS раскрывает последовательности от сотен до тысяч генов или областей генов одновременно, обеспечивая повышенную чувствительность к редким комбинациям генов, повышение скорости обработки больших объемов данных, комплексное геномное покрытие [1]. Последующее снижение затрат на осуществление исследований и повышение достоверности получаемых результатов связывается с технологиями третьего поколения, к числу которых относятся: «tSMS" (true Single Molecule Sequencing - технология секвенирования одной молекулы; "SMRT» (Single Molecule RealTime - секвенирование единичных молекул в реальном времени); nanopore sequencing (секвенирование через нанопоры) [2].

Если оценивать принципиальную воз- можность использования результатов генетических тестов для целей страхования, необходимо учитывать, что стоимость исследования коррелируется с объемом получаемой информации, в силу чего особое значение приобретает определение формата генетического исследования, который может быть связан с секвенированием панели генов, секвенированием экзома и секвенированием генома. Наиболее информативным является полногеномный анализ (WGS), который затрагивает участки, обычно выпадающие из поля зрения специалистов, в силу чего при некоторых видах заболеваний (например, туберозный склероз или синдром Альпорта) ему нет полноценной альтернативы [3]. Однако затраты на него в России составят от 99 до 120 тысяч рублей, а результаты будут получены в срок от 72 до 130 дней $[4,5,6]$. Полное секвенирование экзома, заключающееся в считывании кодирующей последовательности всех генов с последующим избирательным анализом в отношении конкретного набора генов, определяемого проверяемым диагнозом, признается эффективным для диагностики наследственных опухолевых синдромов, эндокринопатий, неврологических заболеваний и первичных иммунодефицитов. Это исследование в 1,5-2 раза менее затратно, но также занимает от 90 до 130 дней $[7,8,9]$.

В силу этого в клинической практике приоритет отдается таргетному секвенированию (посредством секвенирования генных панелей, секвенирования РНК и др.). Перспективным методом исследования, имеющим множество модификаций (PLAC-seq, Nano-ChIP-seq, ChIP-exo, ChIP-nexus, CLIP-seq и др.), является использование ДНК-биочипов (ДНК-чипов, PHК-чипов, белковых и клеточных микрочипов), позволяющих одновременно осуществлять многопараметрический анализ значительного числа генов (белков и других субстанций), используя сравнительно небольшое количество исходного
75 
материала[10]. При этом его стоимость в разы ниже цены полногеномного и полноэкзомного секвенирования, что обеспечивает возможность массового внедрения для оценки многочисленных факторов, обусловливающих предрасположенность к ряду мультифакторных заболеваний (артериальной гипертензии, остеопороза, бронхиальной астмы и пр.). Однако это не решит всех проблем, особенно в случаях, когда генетические заболевания возникают вследствие мутаций de novo, представляющих собой наследственные дефекты, возникающие вследствие естественного мутагенеза непосредственно у ребенка, выявление которых возможно только при проведении экзомного секвенирования как у ребенка, так и его родителей.

Кроме того, несмотря на б льшую информативность, результаты генетических тестов не имеют существенных преимуществ с точки зрения совершенствования качества прогнозов развития многофакторных заболеваний по сравнению с традиционными методиками. Вместе с тем, риски страховщиков отчасти могут быть нивелированы по мере расширения практики генетического тестирования, приводящей к формированию некой общей картины в отношении соответствующей популяции посредством формирования биобанка данных, которая позволит, не обращаясь к персональным данным, использовать статистические закономерности для актуарных расчетов. Это, помимо прочего, позволяет решить проблемы недискриминации и обеспечения защиты персональных данных, составляющих серьезную этическую проблему при использовании генетических данных в страховании.

Острота этой проблемы в странах с развитыми рынками личного страхования потребовала соответствующей реакции законодателя, хотя единого подхода к ее решению не сложилось. В одних случаях, речь идет об установлении запрета дискриминации по признаку генетических характеристик в контексте общих положений законодательства о правах человека (США), в других, о создании специальных предписаний для страховых компаний, которым в том числе с позиции биоэтики, может быть запрещено требовать от страхователя проведения генетического тестирования или предоставления результатов предыдущих тестов(Австрия, Норвегия, Франция), в том числе в контексте охраны прав на защиту персональных данных третьих лиц (Испания, Португалия).
В то же время в некоторых юрисдикциях реализуется более гибкий подход, где, при общем запрете на запрос результатов генетических тестов и побуждение к его прохождению, для защиты интересов страховщиков оговаривается, что эти правила не распространяются на случаи страхования жизни, страхования на случай инвалидности (в том числе на производстве) и страхование на случай длительного ухода, если размер предполагаемой выплаты превышает установленные пределы (Австралия, Великобритания, ФРГ). В то же время законодатель может пойти от обратного, определив обстоятельства, при которых страховщик не вправе получать и использовать уже имеющиеся результаты генетического тестирования, в том числе независимо страховой суммы. Как правило, речь идет о случаях обязательного страхования. Так, положения Федерального закона Швейцарии «О генетическом анализе человека» (LAGH) 2018 года [11], согласно которым страховщик не вправе получать и использовать уже имеющиеся результаты генетического тестирования, если речь идет о социальном страховании, обусловлены необходимостью обязательного страхования в отдельных сферах профессиональной деятельности либо связаны со страхованием обязанности выплачивать заработную плату в случае болезни или материнства.

Помимо этого, в Австралии и Великобритании страхователям предоставляется возможность влиять на условия и характер использования информации об их здоровье, в том числе предоставлять данные генетических тестов для исключения негативного фактора, вытекающего из семейного анамнеза.

Весьма специфичная практика реализуется в Израиле, где с 2006 года формируется национальная генетическая база данных, получаемых в результате исследований, проводимых в рамках реализуемой с 1980 года Национальной программы по выявлению и профилактике врожденных дефектов. Она включает краткие клинические резюме, дифференцируемые в отношении разных национальных общин (евреи-ашкенази; евреи, подразделяемые по стране происхождения, мусульмане-бедуины и мусульмане - не бедуины). И учитывая, что законодательный запрет установлен только в отношении идентифицированной генетической информации, предполагается, что для страховщика не исключается возможность расчета риска на основе генетической характеристики отдельной популяции, 
представителем которой является обратившееся лицо [12]. Если предполагается заключение договора страхования жизни, здоровья, включая риск наступления инвалидности на сумму, превышающую размер, установленный Министерством финансов для любого подобного страхования, страховщику предоставляется право получить от заявителя информацию о прохождении генетического обследования по поводу заболеваний, перечень которых определяет Министерство здравоохранения в течение трех лет, предшествующих подаче такого заявления на страхование.

Следует отметить, что биобанки, охватывающие национальные когорты в $\mathrm{Ce}$ верной Америке, Европе и Азии, создаются и в других государствах, позволяя выявить отдельные статистические закономерности, значимые с точки зрения страхования. Особое значение придается Британскому биобанку, представляющему собой национальный и международный ресурс, изначально созданный с целью улучшения профилактики, диагностики и лечения широкого спектра серьезных и опасных для жизни заболеваний, включая рак, сердечные заболевания, инсульт, диабет, артрит, остеопороз, глазные расстройства, депрессию и формы деменции. Богатый фенотипический охват различных групп населения позволил установить относительно достоверные взаимосвязи между отдельными патологическими состояниями и риском развития конкретного заболевания, создав предпосылки для обобщающей оценки значимости генетических и негенетических факторов риска. Как представляется, подобный опыт заслуживает внимания, поскольку позволяет избежать многих этических проблем, возникающих при решении вопроса о возможности использования генетической информации при осуществлении личного страхования.

В целом, анализ зарубежного законодательства показывает целесообразность регулирования вопросов использования результатов генетических исследований в страховании, что отвечает интересам обеих сторон, устраняя правовую неопределенность, особенно в условиях развития законодательства о защите персональных данных. При этом нельзя не отметить, что государствами выбираются различные правовые средства для определения оснований и пределов использования данных генетического тестирования. В одних, акцент делается на законодательном регулировании, которое в случае федеративного устройства государ- ства может осуществляться на различном уровне (США, Канада), в других, большее значение придается саморегулированию (Великобритания, Австралия).

Изучение законов штатов США наряду с федеральным Законом о недискриминации в отношении генетической информации (GINA) 2008 года показало возможность существования принципиально разных подходов к решению вопроса о пределах использования данных генетических исследований, следствием чего является выработка различных условий страхования в зависимости от территории, на которой заключается договор, что представляется недопустимым. Передача на уровень субъектов федерации вопросов регулирования страхования в Канаде вовсе привело к постановке вопроса о конституционности Закона о недискриминации в области генетики от 4 мая 2017 года, который, по мнению прокуроров нескольких провинций, посягает на юрисдикцию последних, устанавливая уголовную ответственность за нарушение страховщиками предусмотренных в нем предписаний [13].

Как представляется, вопросы, затрагивающие права человека на неприкосновенность частной жизни, включая право на защиту персональных данных, в случае законодательного решения проблемы использования данных генетических исследований в страховании, должны решаться на федеральном уровне в целях обеспечения конституционного принципа равенства прав и свобод человека и гражданина. Впрочем, для России этот аспект рассматриваемой проблемы не столь актуален, учитывая, что в силу положений ст. 71 Конституции РФ регулирование и защита прав и свобод человека и гражданина, равно как финансовое регулирование и гражданское законодательство находятся в ведении Российской Федерации.

В то же время заслуживает внимания опыт ряда государств, передавших детализацию вопросов использования результатов генетического тестирования при страховании объединениям страховщиков с сохранением контроля за закрепленными в них положениями со стороны правительства. В частности, Правительство Великобритании и Ассоциация британских страховщиков (АВI) еще в 2001 году достигли соглашения об установлении добровольного моратория на использование результатов прогностического генетического тестирования. В 2018 год его положения нашли свое отражение в Кодексе о генетическом тестировании и страховании [14], который, как предпола-

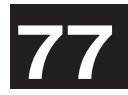


гается, будет действовать бессрочно. В нем формируется дифференцированных подход относительно возможности использования диагностических и прогностических тестов, в силу которого страховщикам предоставляется право требовать раскрытия результатов уже имеющегося прогностического генетического теста и учитывать его результаты, если размер страховых выплат превышает установленные пределы. Дополнительно оговаривается, что получение результатов прогностического генетического теста после начала действия страхового покрытия не является основанием для пересмотра условий договора вопреки обычной практике его изменения в случае выявления обстоятельств, способных повлиять на оценку риска возникновения страхового случая. Если же результат генетического теста предоставляется страховщику заявителем случайно или добровольно, он может принять его во внимание, если это выгодно заявителю. Кроме того, для защиты интересов страховщиков был разработан механизм обжалования фактов неправомерного использования генетической информации.

По такому же пути пошел законодатель и в Австралии, где соответствующие стандарты в свое время выработала Ассоциация инвестиций и финансовых услуг (IFSA). В настоящее время, согласно принятому в 2019 году стандарту FSC № 11 до 30 июня 2024 года, был установлен мораторий на использование генетических тестов при страховании жизни [15]. Вместе с тем, ориентируясь на опыт Великобритании, IFSA предоставила право страховщикам запрашивать или использовать результаты генетического теста, если общая сумма страхового покрытия превышает установленные пределы. Наряду с этим страховщики обязались учитывать благоприятные результаты генетического теста, раскрытые заявителем независимо от объема покрытия, а также влияние научно обоснованного профилактического лечения либо соблюдения научно обоснованных профилактических мер, снижающих вероятность развития болезни

Не без оснований считается, что подобный подход к нормативному регулированию рассматриваемых вопросов является более эффективным в силу формирования достаточно гибкого механизма обеспечения баланса интересов сторон страхового правоотношения в том числе в контексте соблюдения этических требований к обращению с подобной информацией. Действительно, идее актуарной справедливости, последовательно отстаиваемой страховщиками, противостоит необходимость обеспечения равенства граждан независимо от их генетических характеристик, потребность в защите неприкосновенности частной жизни как самого страхователя, так и третьих лиц, неизбежно затрагиваемых при выявлении наследственных заболеваний, а также право на автономию, то есть самостоятельное принятие решения относительно получения информации о своем геноме, включая «право на незнание».

Весьма специфическим аспектом рассматриваемой проблемы является то, что выявление наследственных заболеваний неизбежно затрагивает родственников. Это, с одной стороны, требует нормативного определения пределов использования полученных данных клиента при страховании его родственников, с другой, поднимает вопрос о необходимости их информирования о наследственных заболеваниях, выявленных в ходе генетического тестирования, осуществленного в рамках взаимодействия со страховщиком.

Идея автономии поднимает целый ряд вопросов, наиболее сложным из которых является идея о том, что индивид имеет право оставаться в неведении относительно своих генетических характеристик. «Право на незнание» в одних случаях получает законодательное закрепление (Австрия), в других регламентируется на уровне актов, принимаемых объединениями страховщиков (Австралия). Очевидно, что оно фактически может быть реализовано только в отношении прогностических тестов. Так, в Австрии лицом в любое время может быть сделано заявление о нежелании знать результат анализа и вытекающие из него последствия, а ранее данное согласие на информирование может быть в любой момент отозвано [16]. Правда, в условиях постоянного совершенствования технологий возникает вопрос о последствиях получения вторичных результатов секвенирования генома. Изначально сформировалась позиция, согласно которой по 57 наиболее значимым с точки зрения прогнозирования развития заболевания генам, специалисты обязаны информировать пациента о выявленных рисках [17]. С позиции страхования это влекло бы обязанность страхователя сообщить страховщику об установленных рисках, способных повлиять на вероятность возникновения страхового случая. Однако эта позиция была подвергнута критике ввиду нарушения принципа автономии и в дальнейшем была отвергнута. 
Bce вышеизложенное позволяет прийти к выводу о необходимости нормативного правового регулирования вопросов использования результатов генетических исследований при осуществлении личного страхования. При этом следует исходить из:

1) дифференцированного подхода к диагностическим и прогностическим тестам, распространяя ограничения только на последние;

2) возможности регламентации этих отношений на уровне саморегулирования при контроле ключевых позиций со стороны Центрального банка РФ как регулятора рынка страховых услуг;
3) допустимости использования результатов генетического тестирования в сфере добровольного личного страхования в случае: заключения договора на сумму выше установленных пределов; необходимости опровержения семейного анамнеза с целью выработки более благоприятных условий страхования при наличии соответствующего волеизъявления страхователя;

4) целесообразности создания биобанка данных в том числе с целью обеспечения возможности доступа страховщиков к обезличенной статистической информации.

\section{Литература}

1. Wetterstrand KA. DNA Sequencing Costs: Data from the NHGRI Genome Sequencing Program (GSP) // URL: www.genome.gov/sequencingcostsdata 2. Liu L., Li Y., Li S., Hu N., He Y., Pong R., Lin D., Lu L. and Law M. Comparison of Next-Generation Sequencing Systems // Journal of Biomedicine and Biotechnology. 2012. P. $1-11$

3. Суспицын Е.Н., Тюрин В.И., Имянитов Е.Н., Соколенко А.П. Полноэкзомное секвенирование: принципы и диагностические возможности // Педиатр. 2016. Том 7. Вып. 4. С. 142-146.

4. https://genomed.ru/polnoe-sekvenirovanie-genoma/

5. https://kdl.ru/analizy-i-tseny/polnoe-sekvenirovanie-genoma-genomeuni

6. https://epiclinic.ru/index.php?option=com_quix\&view=page\&id=33

7. https://price.genomed.ru/?testid=554

8. https://kdl.ru/analizy-i-tseny/polnoe-sekvenirovanie-ekzoma;

9. https://dnkom.ru/analizy-i-tseny/dnk/polnoe-sekvenirovanie-ekzoma/

10. Бородулин В.Б., Шевченко О.В., Свистунов А.А. Технология и применение ДНК-биочипов // Известия вузов. Северо-кавказский регион. Естественные науки. 2012. № 1. С. 69-73.

11. Loi f d rale sur l'analyse g $n$ tique humaine(LAGH)du 15 juin 2018 // URL: https:// www.admin.ch/opc/fr/federal-gazette/2018/3627.pdf

12. Zlotogora J. Genetics and genomic medicine in Israel // Mol Genet Genomic Med. 2014 Mar;2(2) S. 85-94.

13. URL: http://www.thecourt.ca/genetic-non-discrimination-act-reference-whatsthe-difference-between-a-genetic-test-and-a-biopsy/

14. Code on Genetic Testing and Insurance, 2018 // URL: https://www.gov.uk/ government/ publications/code-on-genetic-testing-and-insurance

15. FSC Standard No. 11: Moratorium on Genetic Tests in Life Insurance // URL: https://www.fsc.org.au/resources-category/standard/1779-standard-11moratorium-on-genetic-tests-in-life-insurance/file

16. Bundesgesetz, mit dem Arbeiten mit gentechnisch ver nderten Organismen, das Freisetzen und Inverkehrbringen von gentechnisch ver nderten Organismen und die Anwendung von Genanalyse und Gentherapie am Menschen geregelt werden (Gentechnikgesetz - GTG) StF: BGBI. Nr. 510/1994 (NR: GP XVIII IA 732/A AB 1730 S.

168. BR: AB 4827 S. 588.) // URL: https://www.ris.bka.gv.at/GeltendeFassung.wxe ? Abfrage $=$ Bundesnormen\&Gesetzesnummer $=10010826$

17. Green R. C. et al. ACMG Recommendations for Reporting of Incidental Findings in Clinical Exome and Genome Sequencing // Genetics in medicine. 2013. № 15 (7). P. 565-574.

\section{References}

1. Wetterstrand KA. Zatraty na sekvenirovaniye DNK: dannyye programmy NHGRI Genome Sequencing Program (GSP) // URL: www.genome.gov/sequencingcostsdata 2. Lyu L., Li Y., Li S., Khu N., Khe Y., Pong R., Lin D., Lu L. i Lou M. Sravneniye sistem sekvenirovaniya novogo pokoleniya // Zhurnal biomeditsiny i Biotekhnologiya. 2012. P. $1-11$.

3. Suspitsyn Ye.N., Tyurin V.I., Imyanitov Ye.N., Sokolenko A.P. Polnoekzomnoye sekvenirovaniye: printsipy i diagnosticheskiye vozmozhnosti // Pediatr. 2016. Tom 7. Vyp.

4. S. 142-146. 4. https://genomed.ru/polnoe-sekvenirovanie-genoma/

5. https://kdl.ru/analizy-i-tseny/polnoe-sekvenirovanie-genoma-genomeuni

6. https://epiclinic.ru/index.php?option=com_quix\&view=page\&id=33

7. https://price.genomed.ru/?testid $=554$ 
8. https://kdl.ru/analizy-i-tseny/polnoe-sekvenirovanie-ekzoma;

9. https://dnkom.ru/analizy-i-tseny/dnk/polnoe-sekvenirovanie-ekzoma/

10. Borodulin V.B., Shevchenko O.V., Svistunov A.A. Tekhnologiya i primeneniye DNK-biochipov // Izvestiya vuzov. Severo-Kavkazskiy region. Yestestvennyye nauki. 2012. № 1. S. 69-73.

11. Loi $f d$ rale sur l'analyse $g$ n tique humaine (LAGH) ot 15 iyulya $2018 \mathrm{~g}$. // URL: https://www.admin.ch/opc/fr/federal-gazette/2018/3627.pdf

12. Zlotogora Dzh. Genetika i genomnaya meditsina v Izraile // Mol Genet Genomic Med. 2014 Mart; 2 (2) P. 85-94.

13. URL: http://www.thecourt.ca/genetic-non-discrimination-act-reference-whatsthe-difference-between-a-genetic-test-and-a-biopsy/

14. Kodeks geneticheskogo testirovaniya i strakhovaniya, $2018 \mathrm{~g}$. // URL: https:// www.gov.uk/government/publications/code-on-geneticheskoye testirovaniye i strakhovaniye.

15. Standart FSC № 11: Moratoriy na geneticheskiye testy v strakhovanii zhizni // URL: https://www.fsc.org.au/resources-category/standard/1779-standard-11moratorium-on-genetic-tests -v-zhizni strakhovaniye / fayl

16. Bundesgesetz, mit dem Arbeiten mit gentechnisch ver nderten Organismen, das Freisetzen und Inverkehrbringen von gentechnisch ver nderten Organismen und die Anwendung von Genanalyse und Gentherapie am Menschen geregelt werden (Gentechnikgesetz - GTGI) StF. Nr. 510/1994 (NR: GP XVIII IA 732 / A AB 1730 S. 168. BR: AB 4827 S. 588.) // URL: https://www.ris.bka.gv.at/GeltendeFassung. wxe? Abfrage $=$ Bundesnormen \& Gesetzesnummer $=10010826$

17. Grin R. S. i dr. Rekomendatsii ACMG po soobshcheniyu sluchaynykh rezul'tatov klinicheskogo ekzoma i sekvenirovaniya genoma // Genetika v meditsine. 2013. № 15 (7). P. 565-574.

СУВОРОВА Екатерина Ильинична, директор юридического департамента Акционерное общество Страховая компания «Альянс». 115184, г. Москва, Озерковская набережная, дом.30. E-mail: ekaterina.suvorova@allianz.ru

SUVOROVA Ekaterina, Director of the Legal Department, Joint Stock Company Insurance Company "Alliance". 115184, Moscow, Ozerkovskaya embankment, building 30. E-mail: ekaterina.suvorova@allianz.ru 